\title{
Low-calcium diet prevents fructose-induced (1) crosanath hyperinsulinemia and ameliorates the response to glucose load in rats
}

\author{
Anna Voznesenskaya ${ }^{1,2^{*}}$ and Michael G. Tordoff ${ }^{1}$
}

\begin{abstract}
Background: Consuming a fructose-rich diet leads to hyperinsulinemia, impaired glucose tolerance, and insulin resistance. In humans, the consumption of high levels of refined sugars often coincides with a diet containing suboptimal levels of calcium. Calcium and carbohydrate metabolism interact, so there is potential for fructose to have different health outcomes depending on whether the diet is calcium-rich or calcium-poor.

Methods: We evaluated the metabolic effects of feeding fructose to rats that were maintained on either a calcium-replete diet or a low-calcium diet. Growing male Sprague Dawley rats were fed diets based on the AIN-93G formulation, with the main source of carbohydrate derived either from a mixture of cornstarch and sucrose or from fructose. Half the rats given each carbohydrate source were fed calcium at recommended levels $\left(125 \mathrm{mmol} / \mathrm{kg} \mathrm{Ca}^{2+}\right)$; the others were fed a diet low in calcium $\left(25 \mathrm{mmol} / \mathrm{kg} \mathrm{Ca}^{2+}\right)$. At various times, glucose and insulin tolerance tests were conducted to assess glucose metabolism.

Results: Rats fed low-calcium diet had lower fasting insulin levels irrespective of the carbohydrate source they ate. They had a normal glycemic response to a glucose load and did not develop hyperinsulinemia under conditions of fructose feeding. The drop in blood glucose levels in response to insulin injection was larger in rats fed low-calcium diet than in those fed calcium-replete diet.

Conclusions: Low-calcium diet prevented fructose-induced hyperinsulinemia and improved glucose handling under conditions of fructose feeding. Potential mechanisms underlying these effects of the low-calcium diet remain to be determined, but possibilities include impairment of insulin release from the pancreas and improved peripheral insulin sensitivity.
\end{abstract}

Keywords: Calcium, Insulin resistance, Vitamin D, Glucose tolerance, Obesity

\section{Background}

Diet has a major impact on metabolic health, and is a primary factor implicated in metabolic syndrome and Type 2 diabetes $[1,2]$. The drive for energy-dense foods often leads to diets high in sugary drinks and snacks, resulting in high intakes of refined sugars and suboptimal intakes of micronutrients, such as calcium. The deleterious effects of excess consumption of simple sugars on carbohydrate metabolism are well recognized, with contributions made by

\footnotetext{
* Correspondence: anna.voznesenskaya@ki.se
${ }^{1}$ Monell Chemical Senses Center, 3500 Market Street, Philadelphia, PA

* Correspondence: anna.voznesenskaya@ki.se
${ }^{1}$ Monell Chemical Senses Center, 3500 Market Street, Philadelphia, PA 19104-3308, USA

${ }^{2}$ Current address: The Rolf Luft Research Center for Diabetes and Endocrinology, Karolinska Institutet, Karolinska Hospital L1:02, Stockholm SE 17176 , Sweden
}

both the quantity and the type of sugar consumed [2-4]. Due to a general increase in sweetener usage during the last decades of the $20^{\text {th }}$ century, and the popularity of high-fructose corn syrups, fructose consumption in the USA has risen by over $25 \%[5,6]$, although intakes may have decreased slightly in the last few years [7].

Fructose is a simple sugar contained in many food items, either by itself or as a part of the sucrose molecule. Diets rich in fructose induce impaired glucose tolerance accompanied by insulin resistance and hyperinsulinemia [8]. The mechanism underlying fructose-induced metabolic syndrome is complex. It is most likely initiated when fructose induces sustained hepatic gluconeogenesis and lipogenesis, because it bypasses the major regulatory steps 
of the glycolysis pathway $[8,9]$. The action of fructose in the liver is thought to also induce insulin resistance in the periphery, followed by compensatory hyperinsulinemia $[6,10]$.

The progressive increase in intake of high-fructose corn syrup is related to the rise in the consumption of soft drinks, for which it is the main sweetener (e.g., [11]). One other major consequence of the increased intake of sweetened soft drinks is the displacement of milk from the diet [12]. Milk is an important source of calcium, so its disappearance from the diet has exacerbated suboptimal calcium intakes [12, 13]. Calcium deficiency leads to impaired insulin release in experimental animals, and there are indications that the same is true for humans [14-16]; decreases in circulating levels of both calcium and vitamin D are associated with changes in glucose homeostasis [17-19]. Thus, calcium and sugar intake, and their homeostasis are intertwined; however, little is known about how calcium status influences the regulation of metabolism under conditions of sugar overconsumption.

We investigated whether the combination of a highfructose diet along with marginally inadequate calcium might have combined detrimental influences on glucose metabolism. To this end, we compared the metabolic profiles of rats fed diets with the carbohydrate provided either as a standard mixture of cornstarch and sucrose or as fructose, and with the calcium provided either at replete or marginally deficient levels. We found that relative to calcium-replete controls, rats fed low-calcium diet had improved insulin sensitivity and did not develop hyperinsulinemia when fed the highfructose diet.

\section{Methods}

The experiment involved a $2 \times 2$ design: Rats were fed diets containing either 125 or $25 \mathrm{mmol} / \mathrm{kg} \mathrm{Ca}^{2+}$, with the carbohydrate source derived from either a standard sucrose-cornstarch mixture or from fructose. Blood samples were collected at various times, as described below.

The protocol was approved by the Monell Chemical Senses Center Institutional Animal Care and Use Committee.

\section{Subjects}

Two identical cohorts of 36 rats each (72 total) were tested. Male Sprague-Dawley rats were obtained from Charles River (Raleigh, NC) at the age of 21 days. They were housed individually in stainless steel wire mesh hanging cages $(19.5 \times 17.5 \times 24 \mathrm{~cm})$. Unless otherwise noted, pelleted AIN-93G diet modified to contain $125 \mathrm{mmol} \mathrm{Ca}^{2+} / \mathrm{kg}$ (Table 1) and deionized water were provided ad libitum. The vivarium was maintained at $23{ }^{\circ} \mathrm{C}$ on a $12: 12 \mathrm{~h}$ light/dark cycle with lights off at 19:00 and on at 07:00.

\section{Diets}

The composition of the four experimental diets is shown in Table 1. AIN-93G diet is a diet recommended by the American Institute of Nutrition (now the American Society for Nutrition) in 1993 for growing rats. It contains approximately $10 \%$ sucrose and $52 \%$ cornstarch by weight

Table 1 Composition of experimental diets

\begin{tabular}{|c|c|c|c|c|c|c|c|c|c|}
\hline \multirow[b]{2}{*}{ Ingredient } & \multirow[b]{2}{*}{$\mathrm{kcal} / \mathrm{g}$} & \multicolumn{2}{|c|}{ AIN125 } & \multicolumn{2}{|l|}{ AIN25 } & \multicolumn{2}{|c|}{ FRU125 } & \multicolumn{2}{|c|}{ FRU25 } \\
\hline & & $\mathrm{g} / \mathrm{kg}$ & $\mathrm{kcal} / \mathrm{kg}$ & $\mathrm{g} / \mathrm{kg}$ & $\mathrm{kcal} / \mathrm{kg}$ & $\mathrm{g} / \mathrm{kg}$ & $\mathrm{kcal} / \mathrm{kg}$ & $\mathrm{g} / \mathrm{kg}$ & $\mathrm{kcal} / \mathrm{kg}$ \\
\hline Casein & 3.58 & 200 & 716 & 200 & 716 & 200 & 716 & 200 & 716 \\
\hline L-Cystine & 4 & 3 & 12 & 3 & 12 & 3 & 12 & 3 & 12 \\
\hline Fructose & 3.8 & 0 & 0 & 0 & 0 & 617 & 2345 & 627 & 2383 \\
\hline Sucrose & 4 & 100 & 400 & 100 & 400 & 0 & 0 & 0 & 0 \\
\hline Cornstarch & 3.6 & 385 & 1386 & 395 & 1422 & 0 & 0 & 0 & 0 \\
\hline Dyetrose & 3.8 & 132 & 501.6 & 132 & 501.6 & 0 & 0 & 0 & 0 \\
\hline Soybean oil & 9 & 70 & 630 & 70 & 630 & 70 & 630 & 70 & 630 \\
\hline t-Butylhydroquinone & 0 & 0.014 & 0 & 0.014 & 0 & 0.014 & 0 & 0.014 & 0 \\
\hline Cellulose & 0 & 50 & 0 & 50 & 0 & 50 & 0 & 50 & 0 \\
\hline $\begin{array}{l}\text { Mineral Mix \#213019 } \\
\text { (w/o Ca) }\end{array}$ & 0.88 & 35 & 30.8 & 35 & 30.8 & 35 & 30.8 & 35 & 30.8 \\
\hline Vitamin Mix \# 310025 & 3.87 & 10 & 38.7 & 10 & 38.7 & 10 & 38.7 & 10 & 38.7 \\
\hline Choline bitartrate & 0 & 2.5 & 0 & 2.5 & 0 & 2.5 & 0 & 2.5 & 0 \\
\hline Calcium carbonate & 0 & 12.5 & 0 & 2.5 & 0 & 12.5 & 0 & 2.5 & 0 \\
\hline Total kcal per kg & & & 3715 & & 3751 & & 3772 & & 3810 \\
\hline
\end{tabular}

All diets were purchased from Dyets Inc, Bethlehem, PA (catalogue nos: 103660, 103662, 103661, 103663, respectively). Dyetrose is a proprietary dextrinized cornstarch used to facilitate pelleting the diet. The mineral and vitamin mixes yield energy because they are mixed in a powdered sucrose base 
(Table 1). Fructose-based diets were identical to the AIN93G-based diets except that virtually all the carbohydrate was provided as fructose (small amounts of sucrose were used as a vehicle for the mineral and salt mixes). These were provided in either "replete" $(125 \mathrm{mmol} / \mathrm{kg})$ or "low" (25 mmol $/ \mathrm{kg}$ ) calcium concentrations. The $125 \mathrm{mmol} / \mathrm{kg}$ calcium concentration is well above requirements for growth [20, 21]. The $25 \mathrm{mmol} / \mathrm{kg}$ calcium concentration was chosen based on our previous work showing that it effectively reduced blood calcium concentrations and induced the motivation to consume calcium but it did not cause a failure to thrive (e.g., [22, 23]). For convenience, we abbreviate the diets based on their carbohydrate source [i.e., similar to AIN-93G or fructose (FRU)] and the concentration of calcium (125 or $25 \mathrm{mmol} / \mathrm{kg}$ ).

\section{Procedures}

After 3 days to acclimatize to the vivarium environment, the rats were assigned to four groups matched for body weight and the percentage of body weight that was fat, which was assessed using a Bruker Minispec nuclear magnetic resonance analyzer (see below). The experimental diets were introduced in two steps: On Day 0 (at age 24 days), half of the rats were switched to AIN25 diet; the other half remained on AIN125 diet. On Day 3, half of the rats in each AIN125 and AIN25 diet group were switched to fructose-based diets (FRU125 and FRU25). Thus, there were 18 rats in each of the four groups.

The body weight, food intake, and water intake of each rat was recorded daily. Body weight $( \pm 0.1 \mathrm{~g})$ was measured using a top-loading balance. Food intake $( \pm 0.1 \mathrm{~g})$ was based on the difference in weight between food given each day and food remaining the following day; it was corrected for spillage, which was collected under each cage. Body composition was assessed weekly. To accomplish this, each rat was carried to an adjacent room housing a Bruker Minispec LF110, placed into a plastic restraining tube, and then inserted into the core of the machine for $\sim 90 \mathrm{sec}$ while its body composition was assessed by magnetic resonance technology. The rat was then returned to its home cage.

To confirm the development of calcium deficiency, blood ionized calcium levels were measured on Days 10 and 17 , at $\sim 7 \mathrm{~h}$ after the start of the light period. Approximately $70 \mu \mathrm{l}$ of blood was collected from the tip of the tail into a heparin-coated capillary tube (RAPIDLyte Multicap, Siemens) and within $15 \mathrm{sec}$ analyzed using a Rapidlab 348 blood gas analyzer (Siemens, Germany) located in the vivarium. For this and subsequent tests, care was taken to collect blood samples from the rats in an order that controlled for disturbances and any delays between sampling and assaying. To do this, the samples were collected successively from rats in tetrads containing one representative of each of the four diet groups, and the order within each tetrad was counterbalanced.

Fasting blood glucose, insulin and triglyceride (TG) levels were measured in blood samples collected on Days 11, 18 and 42 , at $\sim 7 \mathrm{~h}$ after the start of the light period. Taking into account that young growing rats were relatively small at the beginning of the experiment we opted to use a morning fast instead of more severe overnight food deprivation: In small rodents prolonged overnight fasting induces a catabolic state, and along with standard housing conditions at subthermoneutral temperatures it can decrease metabolic rate [24]. In our experiment, we aimed to collect measurements under less extreme physiological conditions. Rats were fasted for 5-6 h and then a blood sample was collected from the tip of the tail into an EDTA-treated tube. The tubes were centrifuged and plasma glucose and TG levels were analyzed using enzyme-based colorimetric assays (Cayman Chemical, MI). Insulin levels were measured using ELISA (Rat insulin kit \# EZRMI-13 K, EMD Millipore, MA). Sometimes when the rats were young, insufficient blood was collected to conduct all the measurements. In these cases, insulin measurements were given priority.

An oral glucose tolerance test was given between Days $23-25$, at $\sim 7 \mathrm{~h}$ after the start of the light period. After an overnight fast, each rat was gavaged with $8 \mathrm{ml} / \mathrm{kg}$ of $25 \%$ glucose solution $(2 \mathrm{~g} / \mathrm{kg})$. Blood was collected at $0,15,30,60$ and 120 min. Plasma glucose and insulin levels were measured as described above.

An insulin tolerance test (ITT) was given on either Day 36 or 37 , at $\sim 7 \mathrm{~h}$ after the start of the light period. After a $5-6 \mathrm{~h}$ fast, each rat received insulin $[0.75 \mathrm{IU} / \mathrm{kg}$, $0.75 \mathrm{ml} / \mathrm{kg}$, i.p. of $1 \mathrm{IU}$ insulin (HumilinR, Eli Lilly) solution prepared in isotonic saline]. For this test, glucose levels were measured using an Accu-Check Aviva Plus blood glucose meter (Roche Diagnostics).

\section{Data analysis}

Body weights were analyzed using weekly measurements taken on the day of the body composition assessment. Daily food intakes were averaged into weekly blocks, based on the sum of daily measurements divided by the number of days; days when rats were fasted overnight were excluded from analysis.

Areas under the glucose and insulin curves during oral glucose tolerance tests were calculated using the trapezoidal rule $[25,26]$.

Two-way ANOVAs with factors of Diet Carbohydrate and Diet Calcium were used to analyze the area under the glucose and insulin curves. For all other measures, threeway mixed-design ANOVAs were used, with the same two 
between-subject factors and Time as a within-subject factor. When appropriate, differences between pairs of means were assessed using Fisher LSD tests. The criterion for statistical significance was $p \leq 0.05$.

One animal was excluded from the analyses of the oral glucose tolerance test due to unsuccessful gavage of the glucose load. The Week 3 body composition of one rat was lost due to a technical error.

\section{Results}

\section{Body weight and food intake}

All four groups of rats gained weight steadily over the 6 weeks of the experiment, although those fed the low-calcium diets gained less weight than did those fed the calcium-replete diets; the difference was statistically significant at Week 3 and thereafter [Diet Calcium $\times$ Time, $\mathrm{F}(5,335)=99.6, p<0.001]$. The source of dietary carbohydrate did not affect body weight (Fig. 1a). Dietary calcium content had an effect on fat accumulation over time (Diet Calcium $\times$ Time, F $(5,330)=4.1, p \leq 0.05$; Fig. 1b): In all four groups, the proportion of body fat fell from Week 1 to Week 2, but in rats fed the calcium-replete diets the proportion of body fat increased significantly between Week 2 and Week 4, whereas in the rats receiving lowcalcium diets a significant increase above the values for Week 2 did not occur until Week 5 (Fig. 1b). However, there were no significant differences between rats fed calcium-replete and low-calcium diet in the proportion of body fat at any time.

Food intakes reflected the differences in body weight gain: Starting from Week 3, rats fed the low-calcium diets ate significantly less food than did rats fed the calciumreplete diets (Diet Calcium $\times$ Time, F $(5,335)=17.9, p<$ 0.001; Fig. 1c). Fructose affected food consumption on Weeks 2 and 4 only, when the rats fed the fructose-based diet ate more food than did the rats fed the AIN diets [Diet Carbohydrate $\times$ Time, F $(5,335)=2.36, p \leq 0.05$ ]

\section{Fasting blood calcium, insulin, glucose, and TGs}

Rats fed the low-calcium diets were hypocalcemic on Days 10 and 17, F $(1,67)=17.3, p<0.001$, with no difference between the two measurements, suggesting that the diets had their intended effects, and that blood ionized calcium concentrations were stable. There was no effect of the carbohydrate source on blood ionized calcium concentrations (Table 2).

Rats fed the diets containing fructose had elevated fasting glucose levels and markedly elevated TG levels relative to rats fed the AIN-based diets [glucose, $\mathrm{F}(1,62)=13.4$, $p<0.001$; TG, F $(1,50)=36.7, p<0.001]$. There were no effects of dietary calcium on fasting blood levels of glucose or TG at any time; however, fasting insulin levels were lower in rats fed the low-calcium diets than calciumreplete diets, F $(1,64)=6.9, p<0.01$. Fructose-fed rats
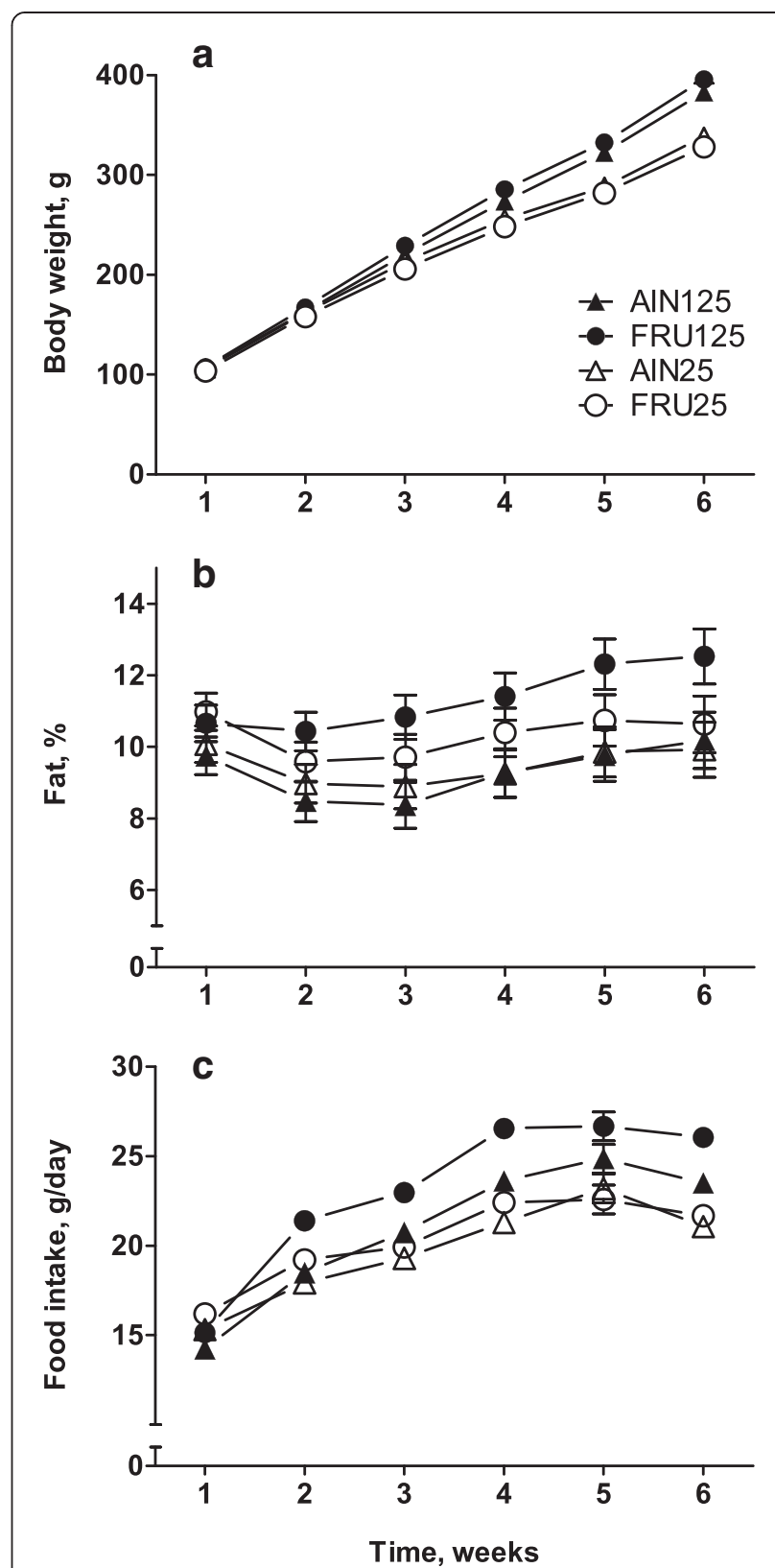

Fig. 1 Body weight (a), body fat (as a proportion of body weight) (b), and food intake (c) of rats fed diets differing in carbohydrate source and calcium content. Symbols with vertical bars represent means \pm SEMs. AlN125-rats fed AIN-93G diet containing $125 \mathrm{mmol}$ $\mathrm{Ca}^{2+} / \mathrm{kg}$, FRU125-rats fed fructose-based diet containing $125 \mathrm{mmol}$ $\mathrm{Ca}^{2+} / \mathrm{kg}$, AlN25-rats fed AlN-93G diet containing $25 \mathrm{mmol} \mathrm{Ca}{ }^{2+} / \mathrm{kg}_{\text {, }}$ FRU25-rats fed fructose-based diet containing $25 \mathrm{mmol} \mathrm{Ca}^{2+} / \mathrm{kg}$. Where error bars are not shown they were smaller than the symbol size

tended to have higher fasting insulin levels than did rats fed the AIN-based diets, F $(1,64)=3.8, p=0.06$. There was no interaction between dietary carbohydrate and calcium [Diet Carbohydrate $\times$ Diet Calcium, F $(1,64)=1.9$, NS; Diet Carbohydrate $\times$ Diet Calcium $\times$ Time, F $(2,128)=0.1$, NS]. All four groups had increasingly higher glucose, 
Table 2 Fasting plasma levels of calcium, insulin, glucose and triglycerides (TG) on various days after introduction of experimental diets

\begin{tabular}{lllll}
\hline & AlN125 & FRU125 & AlN25 & FRU25 \\
\hline $\mathrm{Ca}^{2+}, \mathrm{mg} / \mathrm{dL}^{* * *}$ & & & & \\
Day 10 & $5.60 \pm 0.08$ & $5.68 \pm 0.08$ & $5.36 \pm 0.08$ & $5.28 \pm 0.04$ \\
Day 17 & $5.52 \pm 0.08$ & $5.60 \pm 0.08$ & $5.28 \pm 0.08$ & $5.28 \pm 0.08$ \\
Insulin, $\mathrm{ng} / \mathrm{mL}^{* * \S}$ & & & & \\
Day 11 & $2.0 \pm 0.3$ & $2.6 \pm 0.3$ & $1.9 \pm 0.3$ & $1.9 \pm 0.3$ \\
Day 18 & $2.4 \pm 0.3$ & $3.3 \pm 0.3$ & $2.2 \pm 0.3$ & $2.3 \pm 0.3$ \\
Day 42 & $4.7 \pm 0.5$ & $5.8 \pm 0.4$ & $4.0 \pm 0.5$ & $4.4 \pm 0.5$ \\
Glucose, $\mathrm{mg} / \mathrm{dL}{ }^{\# \S}$ & & & & \\
Day 11 & $101 \pm 4$ & $109 \pm 4$ & $97 \pm 4$ & $105 \pm 4$ \\
Day 18 & $115 \pm 1$ & $126 \pm 4$ & $116 \pm 4$ & $123 \pm 4$ \\
Day 42 & $134 \pm 3$ & $143 \pm 3$ & $129 \pm 3$ & $138 \pm 3$ \\
TG, mg/dL ${ }^{\# \S}$ & & & & \\
Day 11 & $56 \pm 15$ & $134 \pm 16$ & $48 \pm 15$ & $102 \pm 14$ \\
Day 18 & $82 \pm 16$ & $173 \pm 17$ & $61 \pm 16$ & $163 \pm 15$ \\
Day 42 & $98 \pm 18$ & $201 \pm 19$ & $75 \pm 18$ & $153 \pm 16$ \\
\hline
\end{tabular}

Data are presented as mean \pm SEM of $n=14-18$ per group. Blood samples were collected during the light period, after a 5-6 $\mathrm{h}$ fast except for the calcium measurements when rats were in a fed state. ${ }^{* *}$ - main effect of Dietary Calcium $p<0.01$; ${ }^{* *}$-main effect of Dietary Calcium $p<0.001$; \#-main effect of Diet Carbohydrate $p<0.001$; $\S$-main effect of Time $p<0.001$, Day $11<$ Day $18<$ Day42

TG and insulin concentrations as the experiment progressed [effects of Time: glucose, F $(2,124)=71.9$; TG, F $(2,100)=20.9$; insulin $\mathrm{F}(2,128)=75.6 p<0.001]$.

\section{Oral glucose tolerance test}

Dietary fructose and calcium had independent and opposite effects on the elevation of plasma insulin concentrations elicited by the oral glucose load: Fructose feeding increased insulin concentrations whereas the low-calcium diet decreased them (Fig. 2a; Diet Carbohydrate $\times$ Time, F $(4,240)=10.2, p<0.001$; Diet Calcium $\times$ Time, $\mathrm{F}(4,240)=8.1, p<0.001)$. Calcium-replete rats fed fructose had an exaggerated insulin response compared with the other three groups (Fig. 2b, AUC: Diet Carbohydrate $\times$ Diet Calcium, F $(1,67)=4.3, p \leq 0.05)$.

The effect of fructose consumption on plasma glucose concentrations depended on calcium status (Fig. 2c, Diet Carbohydrate $\times$ Diet Calcium $\times$ Time, $F$ $(4,236)=2.5, \quad p \leq 0.05)$. The glucose levels of the FRU125 group were higher than those of the other three groups at $30 \mathrm{~min}$ after gavage, and higher than those of the AIN125 and AIN25 groups, but not the FRU25 group, at $15 \mathrm{~min}$ after gavage. The plasma glucose levels of rats fed the FRU25 diet were similar to those of rats in the other three groups at every time. The area under the curve was smaller in rats fed the low-calcium diets than the replete diets,
F $(1,67)=3.89, \quad p \leq 0.05$ and was higher in the fructose-fed rats than in the rats fed AIN-based diets $\mathrm{F}(1,67)=12.6, p<0.001$ (Fig. 2d).

\section{Insulin tolerance test (ITT)}

Rats fed the low-calcium diets had lower plasma glucose concentrations in response to insulin administration, but this depended on the carbohydrate source (Fig. 3; Diet Carbohydrate $\times$ Diet Calcium $\times$ Time, F $(5,340)=2.2, p \leq$ $0.05)$. Glucose levels at $15 \mathrm{~min}$ after insulin injection were lower in the rats fed AIN25 diet than in those fed AIN125. There were no other differences.

\section{Discussion}

The results demonstrate that fructose-induced hyperinsulinemia and impaired glucose tolerance depend on calcium status: In line with earlier work, plasma insulin concentrations and blood glucose levels in response to a glucose load were markedly elevated in calcium-replete rats fed fructose relative to those fed a standard starchand-sucrose mixture [10]. These effects of fructose feeding were strongly attenuated in rats that received a lowcalcium diet. However, fasting glucose levels in fructosefed rats were not improved by low-calcium feeding. Thus, eating a low-calcium diet significantly alleviated but did not abolish the effects of fructose feeding on glucose handling.

Relative to the calcium-replete fructose-fed rats, the calcium-deficient fructose-fed rats had lower glycemia in response to a glucose load despite a smaller rise in insulin levels. This implies that the response to insulin is less affected by fructose overfeeding under conditions of calcium deficiency. The drop in blood glucose levels in response to insulin injection was larger in rats that received the low-calcium version than calcium-replete version of the AIN-93G diet. This points towards increased insulin sensitivity of the peripheral tissues under conditions of calcium deficiency.

There are at least two plausible mechanisms by which calcium deficiency could influence insulin sensitivity. One involves the activation of insulin receptor expression by high levels of circulating 1,25-hydroxyvitamin $\mathrm{D}_{3}$ [27-29]. An increase in levels of 1,25-hydroxyvitamin $D_{3}$ is a classic effect of calcium deficiency, and it has been observed with the low-calcium diet used here (i.e., AIN25 diet; [30, 31]). Activation of insulin receptor expression through 1,25-hydroxyvitamin $D_{3}$ action would counteract the suppression of insulin receptor responsiveness that is exerted by fructose feeding [32]. The other plausible mechanism involves activation of the osteoblast-specific factor, osteocalcin. Levels of circulating osteocalcin, including the active uncarboxylated form, increase when rats are fed low-calcium diets $[33,34]$. This improves insulin sensitivity in adipose 


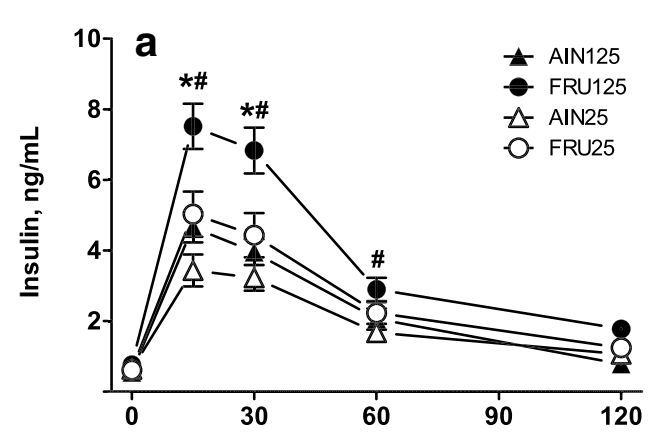

b
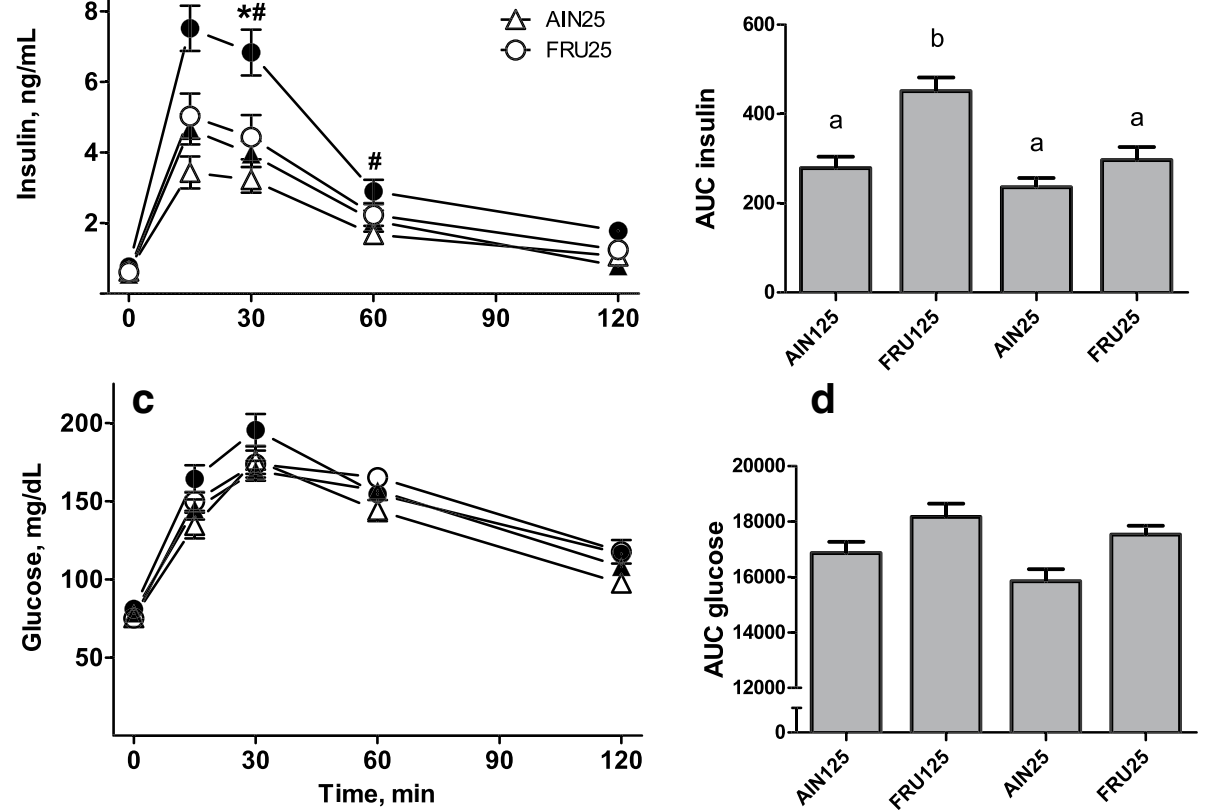

Fig. 2 Oral glucose tolerance test of rats fed diets differing in carbohydrate source and calcium content. Symbols and bars show means \pm SEMs. AUC-area under the curve, AIN125-rats fed AIN-93G diet containing $125 \mathrm{mmol} \mathrm{Ca}{ }^{2+} / \mathrm{kg}$, FRU125-rats fed fructose-based diet containing $125 \mathrm{mmol} \mathrm{Ca}{ }^{2+} / \mathrm{kg}$, AIN25-rats fed AIN-93G diet containing $25 \mathrm{mmol} \mathrm{Ca}{ }^{2+} / \mathrm{kg}$, FRU25-rats fed fructose-based diet containing $25 \mathrm{mmol}$ $\mathrm{Ca}^{2+} / \mathrm{kg}$; groups sharing the same letter did not differ from each other. Changes in plasma insulin levels (a): * Diet Calcium $\times$ Time, $p<0.001$; \# - Diet Carbohydrate $\times$ Time, $p<0.001$. Insulin AUC (b): Diet Carbohydrate $\times$ Diet Calcium, $p \leq 0.05$. Changes in plasma glucose levels (c): 0 no differences; 15 :

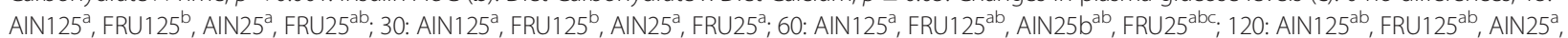
FRU25 ${ }^{\mathrm{ab}}$; Glucose AUC (d): There were no differences between individual means. Diet Carbohydrate $(p<0.001)$ and Diet Calcium $(p \leq 0.05)$ independently affected the glucose AUC

tissue and liver [35]. Consistent with this, injections of osteocalcin improve insulin sensitivity in mice fed highfat diet, which is a metabolic challenge comparable in some of its effects to fructose feeding [36].

Enhanced insulin sensitivity mediated through the action 1,25-hydroxyvitamin $\mathrm{D}_{3}$ and/or osteocalcin may have emerged as an adaptation to conditions when dietary sources of calcium are scarce in order to overcome the secretory deficiency of pancreatic beta-cells induced by low calcium levels.

Reduced fasting insulin levels in rats fed low-calcium diets, and hampered glucose-induced hyperinsulinemia
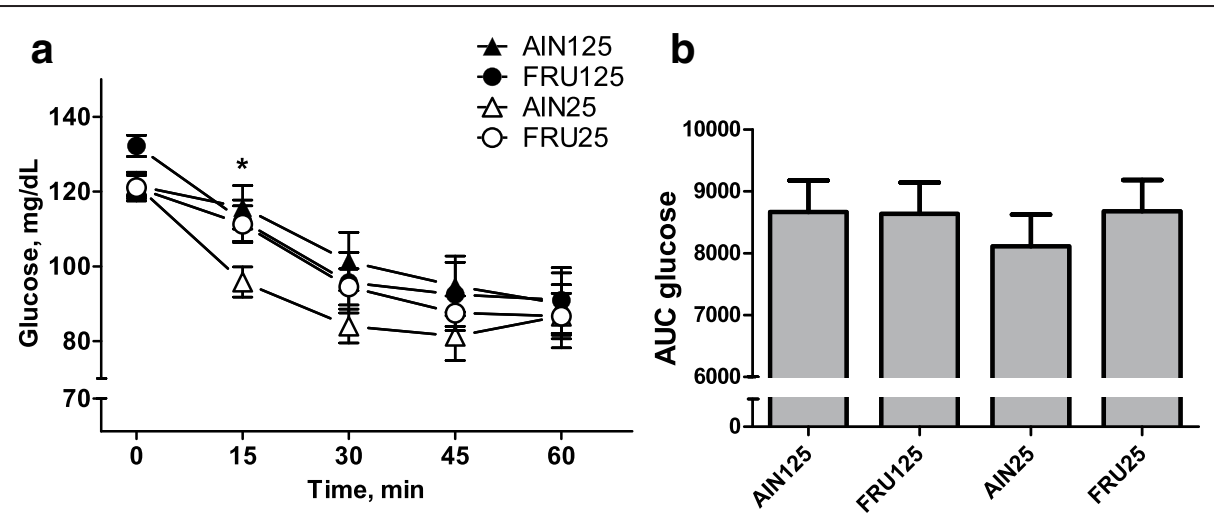

Fig. 3 Insulin tolerance test. Data are means \pm SEMs. AUC-area under the curve, AIN125-rats fed AIN-93G diet containing $125 \mathrm{mmol} \mathrm{Ca}^{2+} / \mathrm{kg}$, FRU125-rats fed fructose-based diet containing $125 \mathrm{mmol} \mathrm{Ca}{ }^{2+} / \mathrm{kg}$, AIN25-rats fed AIN-93G diet containing $25 \mathrm{mmol} \mathrm{Ca}^{2+} / \mathrm{kg}, \mathrm{FRU} 25-\mathrm{rats}$ fed fructose-based diet containing $25 \mathrm{mmol} \mathrm{Ca}{ }^{2+} / \mathrm{kg}$; (a) Changes in plasma glucose levels: ${ }^{*}$-AIN $125^{\mathrm{b}}, \mathrm{AIN}_{25^{\mathrm{a}}, \text { FRU125 }}{ }^{\mathrm{ab}}$, FRU25 $5^{\mathrm{ab}}$. Glucose AUC (b): No significant differences 
in fructose-fed rats receiving low-calcium diets, is consistent with the effect of dietary calcium deficiency to interfere with insulin release [14, 15]. Glucose-induced hyperinsulinemia in fructose feeding may have also been ameliorated by what appears to be improved insulin sensitivity in calcium deficiency: Exaggerated insulin release in fructose feeding is thought to be a compensatory response to the development of insulin resistance in the periphery and thus could potentially be prevented if insulin sensitivity is maintained [6].

Insulin sensitivity is tied to body size, particularly body fat. However, this cannot explain the results found here because differences in insulin release, and the effects of insulin on blood glucose levels, in rats fed the low-calcium and the calcium-replete diets were not related to the proportion of adipose tissue: There were no differences in the proportion of body fat among the experimental groups at any time.

Several studies suggest that, under some conditions, calcium-deficient rodents are more susceptible to obesity than their replete controls [37, 38] but there are also several failures to observe this [31, 39]. The current work falls in the latter camp and supports the conclusion that calcium intake has no direct effect on the development of obesity in rats.

\section{Conclusions}

The experiments reported here reveal that, in rats, a low-calcium diet-despite being harmful in its own ways [40-43] - can counteract the detrimental effects of fructose overconsumption on glucose handling. If this relationship applies to humans, then exhortations to consume more calcium may exacerbate components of metabolic syndrome. The health outcomes caused by excess consumption of high-fructose corn syrup may be influenced as much by the calcium status of an individual as by the amount of the sugar the individual consumes. At the least, the results point to the complexity of nutritional interactions that make giving dietary advice fraught with peril.

\section{Competing interests}

The authors declare that they have no competing interests.

\section{Authors' contributions}

M.G.T and A.V. designed the research; M.G.T. and A.V. conducted the experiments; A.V. analyzed the data; and M.G.T and A.V. wrote the paper. Both authors have read and approved the final manuscript.

\section{Acknowledgements}

We thank John Lees and Tiffany Aleman for their expert technical assistance. The work was supported by the National Institute of Deafness and Other Communication Disorders, Grant DC-10149.

Received: 22 June 2015 Accepted: 3 October 2015

Published online: 29 October 2015

\section{References}

1. Hu FB, Manson JE, Stampfer MJ, Colditz G, Liu S, Solomon CG, et al. Diet, lifestyle, and the risk of type 2 diabetes mellitus in women. N Engl J Med. 2001;345(11):790-7.

2. Gross LS, Li L, Ford ES, Liu S. Increased consumption of refined carbohydrates and the epidemic of type 2 diabetes in the United States: an ecologic assessment. Am J Clin Nutr. 2004;79(5):774-9.

3. Lanaspa MA, Ishimoto T, Li N, Cicerchi C, Orlicky DJ, Ruzycki P, et al. Endogenous fructose production and metabolism in the liver contributes to the development of metabolic syndrome. Nat Commun. 2013;4:2434.

4. Elliott SS, Keim NL, Stern JS, Teff K, Havel PJ. Fructose, weight gain, and the insulin resistance syndrome. Am J Clin Nutr. 2002;76(5):911-22.

5. Popkin BM, Nielsen SJ. The sweetening of the world's diet. Obes Res. 2003:11(11):1325-32.

6. Havel PJ. Dietary fructose: implications for dysregulation of energy homeostasis and lipid/carbohydrate metabolism. Nutr Rev. 2005;63(5):133-57

7. Welsh JA, Sharma AJ, Grellinger L, Vos MB. Consumption of added sugars is decreasing in the United States. Am J Clin Nutr. 2011;94(3):726-34.

8. Lustig RH. Fructose: metabolic, hedonic, and societal parallels with ethanol. J Am Diet Assoc. 2010;110(9):1307-21.

9. Tobey TA, Mondon CE, Zavaroni I, Reaven GM. Mechanism of insulin resistance in fructose-fed rats. Metabolism. 1982;31(6):608-12.

10. Zavaroni I, Sander S, Scott S, Reaven GM. Effect of fructose feeding on insulin secretion and insulin action in the rat. Metabolism. 1980;29(10):970-3

11. Malik VS, Popkin BM, Bray GA, Després J-P, Hu FB. Sugar Sweetened Beverages, Obesity, Type 2 Diabetes and Cardiovascular Disease risk. Circulation. 2010;121(11):1356-64.

12. Vartanian $L R$, Schwartz MB, Brownell $K D$. Effects of soft drink consumption on nutrition and health: a systematic review and meta-analysis. Am J Public Health. 2007:97(4):667-75.

13. Harnack L, Stang J, Story M. Soft drink consumption among US children and adolescents: nutritional consequences. J Am Diet Assoc. 1999;99(4):436-41.

14. Beaulieu C, Kestekian R, Havrankova J, Gascon-Barre M. Calcium is essential in normalizing intolerance to glucose that accompanies vitamin $D$ depletion in vivo. Diabetes. 1993;42(1):35-43.

15. Milner RD, Hales CN. The role of calcium and magnesium in insulin secretion from rabbit pancreas studied in vitro. Diabetologia. 1967;3(1):47-9.

16. Rayssiguier Y, Chevalier F, Gueux E, Remesy C, Demigne C. Glucosestimulated insulin secretion in rats with normal plasma calcium levels: effects of calcium deficiency. J Nutr. 1982;112(9):1801-4.

17. Chiu KC, Chu A, Go VL, Saad MF. Hypovitaminosis D is associated with insulin resistance and beta cell dysfunction. Am J Clin Nutr. 2004;79(5):820-5.

18. Pittas AG, Lau J, Hu FB, Dawson-Hughes B. The role of vitamin D and calcium in type 2 diabetes. A systematic review and meta-analysis. J Clin Endocrinol Metab. 2007:92(6):2017-29.

19. Norman AW, Frankel JB, Heldt AM, Grodsky GM. Vitamin D deficiency inhibits pancreatic secretion of insulin. Science. 1980;209(4458):823-5.

20. Chandler PT, Cragle RG. Investigation of Calcium, Phosphorus and Vitamin D3 Relationships in Rats by Multiple Regression Techniques. J Nutr. 1962;78(1):28-36

21. Bernhart FW, Savini S, Tomarelli RM. Calcium and Phosphorus Requirements for Maximal Growth and Mineralization of the Rat. J Nutr. 1969;98(4):443-8.

22. Tordoff MG. NaCl ingestion ameliorates plasma indexes of calcium deficiency. Am J Physiol Regul Integr Comp Physiol. 1997;273(1 Pt 2):R423-32.

23. Tordoff MG, Okiyama A. Daily rhythm of $\mathrm{NaCl}$ intake in rats fed low-Ca2+ diet: relation to plasma and urinary minerals and hormones. Am J Physiol Regul Integr Comp Physiol. 1996;270(3 Pt 2):R505-17.

24. Ayala JE, Samuel VT, Morton GJ, Obici S, Croniger CM, Shulman Gl, et al. Standard operating procedures for describing and performing metabolic tests of glucose homeostasis in mice. Dis Model Mech. 2010;3(9-10):525-34.

25. Tai MM. A mathematical model for the determination of total area under glucose tolerance and other metabolic curves. Diabetes Care. 1994;17(2):152-4.

26. Allison DB, Paultre F, Maggio C, Mezzitis N, Pi-Sunyer FX. The use of areas under curves in diabetes research. Diabetes Care. 1995;18(2):245-50.

27. Calle C, Maestro B, Garcia-Arencibia M. Genomic actions of 1,25dihydroxyvitamin D3 on insulin receptor gene expression, insulin receptor number and insulin activity in the kidney, liver and adipose tissue of streptozotocin-induced diabetic rats. BMC Mol Biol. 2008;9:65. 
28. Maestro B, Campion J, Davila N, Calle C. Stimulation by 1,25dihydroxyvitamin D3 of insulin receptor expression and insulin responsiveness for glucose transport in U-937 human promonocytic cells. Endocr J. 2000;47(4):383-91.

29. Maestro B, Molero S, Bajo S, Davila N, Calle C. Transcriptional activation of the human insulin receptor gene by 1,25-dihydroxyvitamin D (3). Cell Biochem Funct. 2002;20(3):227-32.

30. Tordoff MG, Hughes RL, Pilchak DM. Calcium intake by rats: influence of parathyroid hormone, calcitonin, and 1,25-dihydroxyvitamin D. Am J Physiol Regul Integr Comp Physiol. 1998;274(1):R214-31.

31. Zhang $Q$, Tordoff MG. No effect of dietary calcium on body weight of lean and obese mice and rats. Am J Physiol Regul Integr Comp Physiol. 2004;286(4):R669-77.

32. Catena C, Giacchetti G, Novello M, Colussi G, Cavarape A, Sechi LA. Cellular mechanisms of insulin resistance in rats with fructose-induced hypertension. Am J Hypertens. 2003;16(11 Pt 1):973-8.

33. Verhaeghe J, Van Herck E, Van Bree R, Van Assche FA, Bouillon R. Osteocalcin during the reproductive cycle in normal and diabetic rats. J Endocrinol. 1989;120(1):143-51.

34. Ferron M, Wei J, Yoshizawa T, Del Fattore A, DePinho RA, Teti A, et al. Insulin signaling in osteoblasts integrates bone remodeling and energy metabolism. Cell. 2010;142(2):296-308

35. Lee NK, Sowa H, Hinoi E, Ferron M, Ahn JD, Confavreux C, et al. Endocrine regulation of energy metabolism by the skeleton. Cell. 2007;130(3):456-69.

36. Ferron M, McKee MD, Levine RL, Ducy P, Karsenty G. Intermittent injections of osteocalcin improve glucose metabolism and prevent type 2 diabetes in mice. Bone. 2012;50(2):568-75.

37. Zemel MB. Regulation of adiposity and obesity risk by dietary calcium: mechanisms and implications. J Am Coll Nutr. 2002;21(2):146s-51s.

38. Zemel MB, Shi H, Greer B, Dirienzo D, Zemel PC. Regulation of adiposity by dietary calcium. Faseb J. 2000;14(9):1132-8.

39. Paradis S, Cabanac M. Calcium deficiency cannot induce obesity in rats. Physiol Behav. 2005;85(3):259-64.

40. Bertone-Johnson ER, Hankinson SE, Bendich A, Johnson SR, Willett WC Manson JE. Calcium and vitamin D intake and risk of incident premenstrual syndrome. Arch Intern Med. 2005;165(11):1246-52.

41. Garland CF, Garland FC, Gorham ED. Calcium and vitamin D. Their potentia roles in colon and breast cancer prevention. Ann N Y Acad Sci. 1999:889:107-19.

42. Weaver CM. Calcium requirements of physically active people. Am J Clin Nutr. 2000;72(2):579s-84s

43. Heaney RP. Lifelong calcium intake and prevention of bone fragility in the aged. Calcif Tissue Int. 1991;49:S42-5.

\section{Submit your next manuscript to BioMed Central and take full advantage of:}

- Convenient online submission

- Thorough peer review

- No space constraints or color figure charges

- Immediate publication on acceptance

- Inclusion in PubMed, CAS, Scopus and Google Scholar

- Research which is freely available for redistribution 